\title{
Multiple Anti-microbial Resistance Profile and Molecular Detection of Some Virulence Genes of Listeria Monocytogenes Isolated from Fresh Raw Meat Retailed in Zaria, Northwestern Nigeria
}

\author{
Olaniyan, S.E. ${ }^{1}$, Kwaga, J.K.P. ${ }^{1}$, Saidu, A.S. ${ }^{2}$, Usman U. ${ }^{1}$ \\ ${ }^{1}$ Department of Veterinary Public Health and Preventive Medicine, Faculty of \\ Veterinary Medicine, Ahmadu Bello University, PMB, 1013, Zaria, 10003, Kaduna \\ State, Nigeria. \\ ${ }^{2}$ Department of Veterinary Public Health and Preventive Medicine, Faculty of \\ Veterinary Medicine, University of Maiduguri, PMB, 1069, Maiduguri-600230, Borno \\ State, Nigeria
}

Corresponding Author Saidu, A.S.

Mobile:

$+2348039359544$

E mail: adamudvm13@gmail.c om

Key words: Antimicrobial resistance, Foodborne infections, Listeria monocytogenes, Virulence genes.
Background and aim: Pathogenic Listeria species are responsible for foodborne diseases and high mortality and morbidity among immunosuppressed humans .

Patients and Methods: A crosssectional study was conducted between March and November 2015 to determine the AMR profile and virulence genes associated with Listeria monocytogenes from beef sold in Zaria. A total of 240 raw beef samples were collected from beef retailers in Zaria city, Tudun-Wada, Danmagaji, Sabon Gari, Kwangila, and Samaru. The samples were transported to the Veterinary Public Health laboratory, $\mathrm{ABU}$, Zaria, for processing. The isolates were further identified as Listeria species by biochemical tests. Antimicrobial susceptibility testing was performed by disc diffusion method. Multiplex PCR was used to identify the virulence genes associated with Listeria monocytogenes. The data were analysed using SPSS
V23.0 and Microsoft Excel version 2019 for Windows 10 . Odd ratio and 95\% CI were determined. Value of $\mathrm{P}<0.05$ was considered significant.

Results: Four different Listeria species were recovered from 66/240 (27.5\%) meat samples. The Listeria species were L. grayi 39(59.1\%), L. innocua 13 (19.7\%), L. monocytogenes 8 (12.5) and L. ivanovii 6 (9.1). High percentages of Cefixime $(87.5 \%)$ and Tetracycline $(87.5 \%)$ susceptibility were found. The $L$. monocytogenes displayed high rate of resistance to Ampicillin (100\%) and gentamicin $(87.5 \%)$. Isolates from Sabongari, Tudun-Wada, and Zaria city had the highest Multiple AMR index (0.73). Two virulence genes were also identified: inlA $1(12.5 \%)$ and iap $5(62.5 \%)$.

Conclusion: This revealed that Listeria monocytogenes prevalent in meat samples in Zaria have multiple AMR, and possess virulence genes

\section{INTRODUCTION}

Listeria is a foodborne bacterial pathogen responsible for listeriosis in humans and animals worldwide [1, 2]. Listeria infection is associated with severe illness and a high mortality rate, especially in the young, elderly and immunosuppressed individuals [3]. It is a relatively rare disease with 0.1 to 10 cases per 1 million people per year depending on the countries and regions of the world. Although the number of cases of listeriosis is small, the high rate of death associated with this infection makes it a significant public health concern [4]. Food is recognized as the most crucial vehicle for listeriosis outbreaks in humans [5]. According to the WHO fact sheets [4], several outbreaks of listeriosis globally, have been linked to the consumption of different foods, including foods of animal origin (meat and dairy products) [6] and high-risk foods include deli meat and ready-to-eat meat products (such as cooked, cured and/or fermented meats and sausages), soft cheeses and cold smoked fishery products. Listeria 
have an exceptional resistance to adverse environmental conditions (low and high temperature, extreme $\mathrm{pH}$ and salinity) which explains their ability to colonize different ecological niches and high capacity of being introduced into the food chain through contaminated food of animal origin and other food products [7].

There are increasing studies from various parts of the world to assess the contamination of meat and food with Listeria and the antimicrobial resistance profiles of such isolates $[\mathbf{8 , 9}]$.

Meat is exposed to bacterial contamination during carcass processing at the abattoir. The sources of these contaminants may be exogenous from the skin or environment or endogenous from gastrointestinal contents. Milk and dairy products remain the most extensively studied foodborne Listeriosis [10]. However, research is scarce regarding listeriosis in raw meat in developing countries like Nigeria.

Listeriosis in Nigeria is not currently a notifiable disease. Moreover, facilities for rapid diagnosis are lacking. Hence, a neglected foodborne illness [11]. However, Ishola had reported an overall prevalence of $91.8 \%$ L. monocytogenes contamination was obtained comprising $91.5 \%$ (390/426) in cloacal swabs and 95.8\% (23/24) in meat. The non-listing of listeriosis as a notifiable disease and the absence of screening at the abattoir and hospital may account for the few reports of listeriosis outbreaks and may even result in underreporting and underestimation of the public health and economic problem of the disease in Nigeria [12]. Beef is a common source of animal protein in Northern Nigeria, and therefore its contamination with Listeria, especially L. monocytogenes, poses crucial public health concerns and risks to consumers. Despite the availability of similar surveys in other parts of the World and Nigeria, studies on isolation and characterisation of Listeria from meat in Northern Nigeria are limited to few studies $[9,13]$. Information about the occurrence, resistance and virulence determinants found in Listeria monocytogenes from meat helps understand and control foodborne illnesses and the emergence of antimicrobial resistance. Ingestion of undercooked meat contaminated with these bacteria may pose a risk to human health. Hence, the present study's objectives were to determine the occurrence of Listeria species in raw meat retailed in different parts of Zaria and to assess the virulence potential and susceptibility of $L$. monocytogenes isolates to selected antimicrobials used for treating listeriosis.

\section{MATERIALS AND METHODS}

\section{Study area:}

The study was carried out in Zaria Nigeria (Latitude: $11^{\circ} 06^{\prime} 40.61^{\prime \prime} \mathrm{N}$, Longitude: $7^{\circ} 43^{\prime}$ 21.72" E) between March and November 2015.

\section{Study design:}

A cross-sectional study was designed to check for food-borne Listeria species in raw meat in Zaria metropolitan. The two Local Government Areas (Sabon Gari and Zaria) that make up the study area constituted the sampling frame. Samples of raw meat were purchased from retail outlets in six (6) different locations/districts were selected. These are Danmagaji, Zaria city, Tudun Wada, Samaru, Kwangila and Sabon Gari. Samples were collected by convenience sampling technique, as presented in figure 1 below.

\section{Sample Size Determination:}

The sample size of the study was determined using the online software (Sample Size Calculator for Estimating a Proportion (statulator.com), Statulator@ Statistical Program [14]. Accessed 28th October, 2021. The earlier reported prevalence of $4.0 \%$ in raw fresh meat in Zaria [13], was used as the expected proportion. The statistical power of $80 \%$ was assumed and alpha (a) level; precision or margin of error considered at 0.05. Based on the above assumptions, a minimum sample size of 59 raw meat was therefore required.

Alternatively, sample size was also calculated using the formula revised by [15] at a confidence level of $95 \%$.

However, for this work, a total of 240 samples were taken, since the minimum sample required is 59 . 


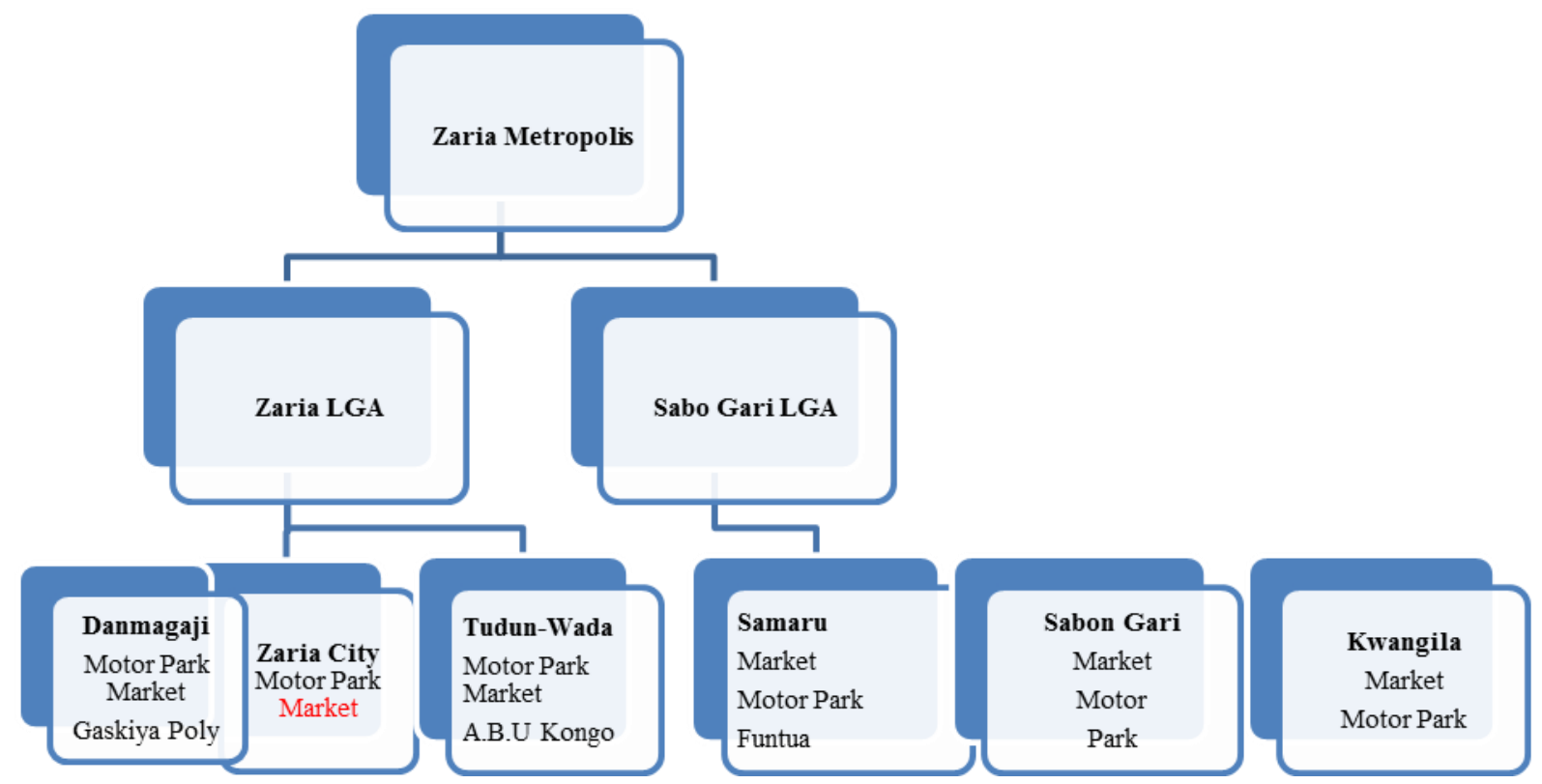

Figure 1: Schematic representation of the sampling areas and Sampling Frame

\section{Sample collection:}

A total of Two hundred and forty (240) fresh meat samples were conveniently purchased as they are customarily packaged and sold as ready to take home meat. Forty (40) samples were collected from each district market listed above. These samples were collected and labelled and placed in a flask containing ice packs, transported to the laboratory on ice and processed for the isolation of Listeria species within two hours of collection.

A pair of disposable hand gloves was used in handling each sample to avoid crosscontamination. For maintenance of microbial load according to the American Public Health Association (APHA) compendium of methods for the microbial examination of foods [16] before they were transported to the Bacterial Zoonoses Laboratory of the Department of Veterinary Public Health and Preventive Medicine, Faculty of Veterinary Medicine, Ahmadu Bello University, Zaria.

\section{Isolation and Identification of Listeria:}

Listeria isolation and identification were performed using the United States Food and Drug Administration and Centre for Food Safety and Applied Nutrition's methods [17]. Briefly, a 10gram portion of each fresh meat sample was added to $90 \mathrm{~mL}$ of Listeria enrichment broth containing selective Listeria enrichment supplement (Oxoid, UK). The mixture was homogenized in a stomacher bag and incubated for $24 \mathrm{~h}$ at $37^{\circ} \mathrm{C}$ for selective enrichment. Next, a loopful of the enrichment broth was streaked onto Listeria selective agar containing selective Listeria enrichment supplement (Oxoid, UK) and incubated at $37^{\circ} \mathrm{C}$ for $24 \mathrm{~h}$. Colonies appearing brown were considered presumptive Listeria spp. Presumptive Listeria colonies were subcultured on tryptone soya agar (TSA).

\section{Biochemical tests:}

According to conventional biochemical tests, biochemical characterization was carried out and included; gram stain, catalase, oxidase, motility and sugar fermentation tests, which included Rhamnose, Mannitol, Maltose and Sucrose. Typical colonies of different species were transferred to TSA plates and incubated for 24hours. Colonies from the TSA plates were preserved on TSA agar slants at $-4^{\circ} \mathrm{C}$ for further tests [18].

\section{Identification of Listeria by the MicrogenR 12L System:}

Microbact ${ }^{\mathrm{R}}$ Listeria 12L Kit (Oxoid, France) was used according to the manufacturer's instructions as a confirmatory biochemical test for $\mathrm{L}$. monocytogenes. All isolates were sub-cultured on TSA at $37^{\circ} \mathrm{C}$ for 24 hours. One colony was picked using a sterile inoculating loop and thoroughly dissolved into the 'manufacturer's broth. The covers were removed, and $100 \mu$ l of suspension containing the organisms were inoculated into impregnated wells using disposable sterile pipette tips for each sample, after which they were then covered again and incubated for 24 hours at $37^{\circ} \mathrm{C}$. A drop of 
haemolysin reagent was added to well 12 of each sample immediately after inoculation. Colour changes were observed and compared with the colour chart provided by the manufacturer. The colour changes were documented as numbers, and the summation of which was inputted into the MicrogenR 12L identification software, which gave the interpretation and the various percentage probabilities of the suspected organisms. Wells labels were corresponding with each isolate labelling code [19].

\section{Antimicrobial Susceptibility Testing (AST):}

Listeria monocytogenes isolates were inoculated into Tryptic soy broth and incubated at $37^{\circ} \mathrm{C}$ aerobically. The actively growing broth culture's turbidity was adjusted with normal saline to obtain turbidity optically comparable to the level of 0.5 MacFarland standards. A sterile swab was then used to evenly spread suspension on the surface of Mueller-Hinton agar. Antibiotic disks (Oxoid, UK), namely; Chloramphenicol-CHL $(25 \mu \mathrm{g})$, Erythromycin-ERY $(5 \mu \mathrm{g})$, Penicillin GPEN (1000 iu), Streptomycin-STREP (10 $\mu \mathrm{g})$, Tetracycline-TET $(25 \mu \mathrm{g})$, Ampicillin-AMP $(10 \mu \mathrm{g})$, Cephalothin- $(5 \mu \mathrm{g}), \quad$ Gentamicin-CN $(10 \mu \mathrm{g})$ and Sulphamethaxozole/trimethoprimSTX $(10 \mu \mathrm{g})$ were placed onto the medium with a disk dispenser. The zones of inhibition that were measured using a transparent ruler. According to the Clinical Laboratory Standards [20] guidelines, the antimicrobial susceptibility testing standards were used to derive a correlation between the zone of inhibition diameters measured to the nearest millimetre and interpreted as resistant, intermediate or sensitive. Multidrug-resistance (MDR) was defined as isolates resistant to at least three different classes of the antimicrobial agents tested.

\section{DNA Extraction Using Qiagen Kit Method:}

Following the overnight culture of each strain, DNA was extracted using Qiagen DNAExtraction Kit (Qiagen, Germany) according to the manufacturer's instructions. A cell lysis step prior to DNA extraction was carried out and consisted of incubation of the bacterial cells in lysis buffer $(20 \mathrm{Mm}$ Tris- $\mathrm{HCl}, \mathrm{pH} 8.0 ; 2 \mathrm{Mm}$ EDTA, pH 8.0; $1.2 \%$ TritonR- 100; $20 \mathrm{mg} / \mathrm{ml}$ lysozyme) for 1 hour at $37 \mathrm{oC}$. The final eluted DNA was stored at $-20 \circ \mathrm{C}$ until further use.

\section{DNA Extraction Protocol:}

Two colonies of each isolate were picked, inoculated into 5mls of Luria Bertani (LB) and incubated at $37^{\circ} \mathrm{C}$ for $24 \mathrm{hrs}$. Then $1500 \mu \mathrm{l}$ of the broth culture was dispensed into sterile Eppendorf tubes and centrifuged at $8 \mathrm{~g}$ for 2 minutes to obtain bacterial cells, and $1000 \mu$ l of the broth culture each of the eight Listeria monocytogenes isolates was added again into Eppendorf tubes containing decant and centrifuged at $8 \mathrm{~g}$ for 2 minutes to obtain bacterial cells. The supernatant was discarded, $400 \mu \mathrm{l}$ of lysis buffer was added to the tube, and the contents were thoroughly mixed and incubated at $70^{\circ} \mathrm{c}$ for 20 minutes. The tube and its contents were centrifuged for 2 minutes at $8 \mathrm{~g}$. The supernatant was then transferred to a spin column and centrifuged, after which $300 \mu \mathrm{l}$ of wash buffer I (Qiagen) was added and the tube was centrifuged at $8 \mathrm{~g}$ for another 2minutes. Subsequently, $300 \mu \mathrm{l}$ of wash buffer II was added, and the tube was centrifuged at $8 \mathrm{~g}$ for 2 mins. The flow-through from the collection tube was discarded, and this step was repeated. The spin column was centrifuged empty to remove the excess buffer. The spin-column was then transferred to clean Eppendorf tubes, $50 \mu 1$ of TE elution buffer was then added to the column matrix, and this was allowed to stand for one minute before it was centrifuged at $8 \mathrm{~g}$ for another 2 minutes. This step was repeated by adding $30 \mu \mathrm{l}$ of the elution buffer, and the pure DNA was collected in the Eppendorf tubes. The extract was then run on an agarose gel to confirm the presence of DNA [21, 22].

\section{PCR Amplification and Detection of Virulence genes:}

Multiplex PCR amplification of the targeted fragments of the virulence specific genes (hylA, inlA and iap) was done by PCR using reverse and forward primers as presented in Table $1[23]$.

$1 \mu \mathrm{l}$ DNA template, $5 \mu \mathrm{l}$ Q-buffer, $2.5 \mu \mathrm{l} \times 10$ buffer, $2 \mu \mathrm{l} 25 \mathrm{mM} \mathrm{MgCl} 2,4 \mu \mathrm{l} \times 10 \mathrm{mM}$ dNTPs,

$0.5 \mu \mathrm{l}$ of each primer $(50 \mathrm{pmol} / \mu \mathrm{l}), 0.125 \mu \mathrm{l}$ HotStarTaq plus DNA polymerase (Qiagen, Hilden, Germany), and was made up to $25 \mu \mathrm{l}$ with ultra-pure water [24].

The reaction mixture was then heated in the thermocycler using the following amplification procedure: $95^{\circ} \mathrm{C}$ for $15 \mathrm{~min}$ for initial denaturation, followed by 35 cycles at $94^{\circ} \mathrm{C}$ for 1 min, $62^{\circ} \mathrm{C}$ for $1 \mathrm{~min}$, and $72^{\circ} \mathrm{C}$ for $1 \mathrm{~min}$. After the last cycle, the samples were incubated at $72^{\circ} \mathrm{C}$ for $10 \mathrm{~min}$. During this experiment, the control strain of L. monocytogenes ATCC 19117 
was used as a positive control and nuclease (Dnase) free water as a negative control. PCR amplification products were fractionated by electrophoresis in 2.0\% agarose gel (Promega, USA) in 1 xTBE $\mathrm{pH} 8 \cdot 3$ at $6 \mathrm{~V} / \mathrm{cm}$ for $15-20$ minutes, and visualized by staining with ethidium bromide.
The Listeria monocytogenes isolates were screened for the hylA, inlA and iap genes by multiplex polymerase chain reaction (m-PCR) using the primers and previously described conditions, as presented in Table 1 below.

Table 1: Listeria monocytogenes isolates specific-primers for the hylA, inlA and iap genes and Conditions for the Multiplex PCR.

\begin{tabular}{|c|c|c|c|c|}
\hline Parameters & Oligonucleotide sequences (5'-3')) & Length & Genes & Reference \\
\hline $\begin{array}{l}\text { Forward primer }(\mathbf{F}) \\
\text { Reverse primer }(\mathbf{R})\end{array}$ & $\begin{array}{l}\text { CCTAAGACGCCAATCGAA } \\
\text { AAGCGCTTGCAAGTCCTC }\end{array}$ & 702 bp & hylA & [23] \\
\hline $\begin{array}{l}\text { Forward primer }(\mathbf{F}) \\
\text { Reverse primer }(\mathbf{R}) \\
\end{array}$ & $\begin{array}{l}\text { ACAAGCTGCACCTGTTGCAG } \\
\text { TGACAGCGTTGTTAGTAGCA }\end{array}$ & $131 \mathrm{bp}$ & iap & [23] \\
\hline $\begin{array}{l}\text { Forward primer }(\mathbf{F}) \\
\text { Reverse primer }(\mathbf{R}) \\
\end{array}$ & $\begin{array}{l}\text { AGATCTAGACCAAGTTACAACGCTTCAG } \\
\text { TAATATCATTTGCTGTTTTATCTGTC }\end{array}$ & $255 \mathrm{bp}$ & inlA & [24] \\
\hline \begin{tabular}{|l|} 
Protocol: \\
Initial Denaturation \\
Denaturation \\
Annealing \\
Extension \\
Final extension \\
\end{tabular} & $\begin{array}{l}95^{\circ} \mathrm{C} \text { for } 5 \text { minutes } \\
94^{\circ} \mathrm{C} \text { for } 1 \text { minute } \\
55-68^{\circ} \mathrm{C} \text { for } 30 \text { seconds } \\
72^{\circ} \mathrm{C} \text { for } 1 \text { minute } \\
72^{\circ} \mathrm{C} \text { for } 5 \text { minutes }\end{array}$ & & $\begin{array}{c}35 \\
\text { cycles }\end{array}$ & \\
\hline
\end{tabular}

\section{Ethical consideration:}

Permission and approval to carry out the study was obtained through the verbal consent.

\section{Data analysis:}

The data obtained were presented in tables using the Microsoft Excel version 2019 for Windows 10 and the Statistical Package for Social Sciences (SPSS version 23.0) was used for the analyses.

Odd ratio (OR) and 95\% CI were used to determine the upper and lower limits among the variables and values where $\mathrm{P} \leq 0.05$ were considered significant.

\section{RESULTS:}

\section{Prevalence and Distribution of Listeria monocytogenes in Raw Meat in Zaria:}

Two hundred and forty raw meat samples collected yielded 66 isolates of Listeria species based on conventional biochemical tests giving us an overall prevalence rate of $27.5 \%$. The raw meat from Tudun-Wada market had the highest isolation rate of $47.5 \%$, Zaria city $32.5 \%$,
Samaru market 30\%, Sabon gari market 25\%, and Dan-magaji yielded $17.5 \%$ while Kwangila market recorded the lowest isolation rate of $12.5 \%$ (Table 2).

\section{The isolation rate of Listeria species from raw meat in Zaria:}

Out of 240 fresh meat samples from all the retail outlets examined in the study, $66(27.5 \%)$ were identified as Listeria species, in which only 8 (3.33\%) isolates were confirmed to be $L$. monocytogenes. However, L. grayi had 39 (16.3\%), L. innocua having13 (5.4\%) and the least was L. ivanovii $6(2.5 \%)$ by biochemical tests and isolation (Table 2). The distribution of the isolates by organ showed that the reproductive tract and GIT had the highest isolation rates of $40.0 \%$ and $33.8 \%$ respectively. The liver had the least isolation rate of $13.6 \%$ (Table 3).

\section{Determination of Susceptibility to Commonly Used Antimicrobial Agents:}

All the Listeria species were resistant to at least 3 out of the 11 commonly used antimicrobial agents tested. However, the majority of the isolates were susceptible to aminoglycosides: 
gentamicin, Kanamycin and ciprofloxacin. The details are presented in Table 4 and 5.

All the eight (8) L. monocytogenes isolates were resistant to one or more of the 11 antimicrobial agents used, with a high level of beta-lactam antimicrobial agent resistance. Resistance was also observed with ciprofloxacin, gentamicin, chloramphenicol and Nitrofurantoin (Table 6).

The susceptibility testing of the eight isolates gave six antimicrobial resistance patterns with $\mathrm{C}$, AMP, AMC, TE, F, SXT, CFM, E and AMP, AMC, CFM having the highest frequency of occurrence followed by CN, AMP, K, AMC, SXT, CFM, E; AMP, TE, F, CFM, EAMP, K, TE, CFM; AMP, AMC, CFM occurring only once. Details of the antimicrobial resistance patterns and multiple antimicrobials resistance profiles are presented in Table 4.

\section{Antimicrobial Resistance:}

In the present study, the Listeria monocytogenes isolates displayed a range of resistance to most of the antimicrobials tested; details are provided in Table 4. However, a large proportion of the isolates were susceptible to Amoxycillin, Cefexime, Erythromycin and Tetracycline (Table 6).

Six of the isolates in this study were multidrugresistant (resistant to $\geq 3$ antibiotics of different classes), with the AMP-AMC-CHL-CFM-ERYF-SXT-TET multidrug resistance phenotype being the most $(n=2)$ occurring pattern (Table 7).

Listeria monocytogenes associated virulence genes inlA 1(12.5\%) and iap 5(62.5\%) were detected from the isolates (Figure 2). However, the hylA gene was not detected.

Table (2): Baseline Occurrence and Distribution of Listeria species in raw meats in Zaria Northwestern, Nigeria.

\begin{tabular}{|l|c|c|c|c|c|c||}
\hline Sampling & \multirow{2}{*}{$\begin{array}{c}\text { Number } \\
\text { Area }\end{array}$} & \multicolumn{5}{|c|}{ Number (\%) of isolates } \\
\cline { 5 - 7 } & samples & L. species & L. monocytogenes & L. grayi & L. innocua & L. ivanovii \\
\hline Samaru & 40 & $12(30.0)$ & $1(8.3)$ & $7(58.3)$ & $5(41.7)$ & $2(16.7)$ \\
Sabon Gari & 40 & $10(25.0)$ & $1(10.0)$ & $6(60.0)$ & $1(10.0)$ & $0(0.0)$, \\
Dan-Magaji & 40 & $7(17.5)$ & $0(0.0)$ & $6(85.7)$ & $0(0.0)$ & $0(0.0)$ \\
Zaria City & 40 & $13(32.5)$ & $1(7.7)$ & $8(61.5)$ & $3(23.1)$ & $3(23.1)$ \\
Kwangila & 40 & $5(12.5)$ & $0(0.0)$ & $3(60.0)$ & $1(20.0)$ & $0(0.0)$ \\
Tudun Wada & 40 & $19(47.5)$ & $5(26.3)$ & $9(47.4)$ & $3(15.8)$ & $1(5.3)$ \\
\hline Total (\%) & $\mathbf{2 4 0}$ & $\mathbf{6 6}(\mathbf{2 7 . 5})$ & $\mathbf{8 ( 1 2 . 5 )}$ & $\mathbf{3 9}(\mathbf{5 9 . 1})$ & $\mathbf{1 3}(\mathbf{1 9 . 7}$ & $\mathbf{6 ( \mathbf { 9 . 1 } )}$ \\
\hline
\end{tabular}

$\mathrm{L}=$ Listeria, $\quad \mathrm{CI}=$ Confidence Interval

Table (3): Occurrence of Listeria species Isolated from various organs/raw meat in Zaria \& Sabo LGAs.

\begin{tabular}{|l|c|c|c|c|c|c|}
\hline \multirow{2}{*}{$\begin{array}{c}\text { Number of Isolates } \\
\text { in meat/organs }\end{array}$} & \multirow{2}{*}{ Meat (Flesh) } & \multicolumn{2}{|c|}{ Number (\%) of isolates, 95\% CI } & \multirow{2}{*}{ Lungs } & \multirow{2}{*}{ Total (\%) } \\
\cline { 3 - 5 } & $\begin{array}{c}\text { Rep Tract } \\
\text { (Female) }\end{array}$ & Liver & GIT & & \\
\hline Number Tested (\%) & $90(37.5)$, & $25(10.4)$, & $22(9.2)$, & $80(33.3)$, & $23(9.6)$, & $240(100)$, \\
& & & & & & \\
No (\%) of Listeria & $19(21.1)$, & $10(40.0)$, & $3(13.6)$, & $27(33.8)$, & $7(30.4)$, & $66(27.5)$, \\
spp, 95\% CI & $12.7-29.5$ & $4.6-17.6$ & $0.7-24.7$ & $23.4-44.1$ & $2.6-15.0$ & $64.2-82.5$ \\
\hline
\end{tabular}

L=Listeria,

$\mathrm{CI}=$ Confidence Interval 
Table (4): Antimicrobial resistance patterns and Multiple Antibiotic Resistance (MAR) index for the Listeria monocytogenes isolates.

\begin{tabular}{|l|c|c|}
\hline \multicolumn{1}{|c|}{ Antimicrobial resistance pattern } & Frequency & MAR index \\
\hline AMC-AMP-CFM & 2 & 0.27 \\
\hline AMP-CFM-KAN-TET & 1 & 0.36 \\
\hline AMP-CFM-ERY-F-TET & 1 & 0.46 \\
\hline AMC-AMP-CFM-CN-ERY-KAN-SXT & 1 & 0.64 \\
\hline AMC-AMP-CIP-ERY-F-KAN-SXT-TET & 1 & 0.73 \\
\hline AMC-AMP-CFM-CHL-ERY-F-SXT-TET & 2 & 0.73 \\
\hline
\end{tabular}

AMC: Amoxycillin/clavulanic acid, AMP: Ampicillin, CFM: Cefexime, C.I.P.: Ciprofloxacin, CHL: Chloramphenicol, CN: Gentamicin, ERY: Erythromycin, F: Nitrofurantoin, KAN: Kanamycin, STX: Sulphamethaxole/Trimethoprim, TET: Tetracycline.

Table (5): Susceptibility of 8 L. monocytogenes from fresh meat to 11 antimicrobials.

\begin{tabular}{|l|l|c|}
\hline \multicolumn{1}{|c|}{ S/No } & \multicolumn{1}{|c|}{ Antimicrobial agent } & No. (\%) of susceptible \\
\hline 1. & Gentamicin & $1(12.5)$ \\
\hline 2. & Chloramphenicol & $4(50.0)$ \\
\hline 3. & Ciprofloxacin & $3(37.5)$ \\
\hline 4. & Ampicillin & $0(0.0)$ \\
\hline 5. & Kanamycin & $3(37.5)$ \\
\hline 6. & Amoxycillin/Clavulanic acid & $6(75.0)$ \\
\hline 7. & Tetracycline & $7(87.5)$ \\
\hline 8. & Nitrofurantoin & $4(50.0)$ \\
\hline 9. & Sulphamethaxozole /Trimethoprim & $4(50.0)$ \\
\hline 10. & Cefexime & $7(87.5)$ \\
\hline 11. & Erythromycin & $5(62.5)$ \\
\hline
\end{tabular}

Table (6): Resistance and Susceptibility of L. monocytogenes $(\mathrm{n}=8)$ from fresh meat to 11 Antimicrobial agents.

\begin{tabular}{|l|c|c|}
\hline \multicolumn{1}{|c|}{ Antibiotics ( $\boldsymbol{\mu g})$} & No. Strains Sensitive (\%) & No. of Strains Resistant (\%) \\
\hline Ampicillin, AMP $(10 \mu \mathrm{g})$ & $0(0.0)$ & $8(100.0)$ \\
\hline Amoxycillin/Clavulanic acid, AMX/CLA $(10 \mu \mathrm{g})$ & $6(75.0)$ & $2(25.0)$ \\
\hline Cefexime, CFM $(25 \mu \mathrm{g})$ & $7(87.5)$ & $1(12.5)$ \\
\hline Chloramphenicol, CHL $(25 \mu \mathrm{g})$ & $4(50.0)$ & $4(50.0)$ \\
\hline Ciprofloxacin, CIP $(5 \mu \mathrm{g})$ & $3(37.5)$ & $5(62.5)$ \\
\hline Erythromycin, ERY $(5 \mu \mathrm{g})$ & $5(62.5)$ & $3(37.5)$ \\
\hline Gentamycin $(10 \mu \mathrm{g})$ & $1(12.5)$ & $7(87.5)$ \\
\hline Kenamycin, KAN $(10 \mu \mathrm{g})$ & $3(37.5)$ & $5(62.5)$ \\
\hline Nitrofurantoin, F $(10 \mu \mathrm{g})$ & $4(50.0)$ & $4(50.0)$ \\
\hline Sulphamethaxole/Trimethoprim, STX $(10 \mu \mathrm{g})$ & $4(50.0)$ & $4(50.0)$ \\
\hline Tetracyclin, TET $(25 \mu \mathrm{g})$ & $7(87.5)$ & $1(12.5)$ \\
\hline
\end{tabular}

AMC: Amoxyllin/clavulanic acid, AMP: Ampicillin, CFM: Cefexime, C.I.P.: Ciprofloxacin, CHL: Chloramphenicol, CN: Gentamicin, ERY: Erythromycin, F: Nitrofurantoin, KAN: Kanamycin, STX: Sulphamethaxole/Trimethoprim, TET: Tetracycline. 
Table (7): Multiple Antibiotic Resistance (MAR.) Index profile for Listeria monocytogenes isolates from raw meat in Zaria metropolis.

\begin{tabular}{|c|c|c|l|c|}
\hline S/No & Isolates ID & $\begin{array}{c}\text { No of antibiotics each } \\
\text { isolate was resistant to } \\
\text { (a) }\end{array}$ & \multicolumn{1}{|c|}{ Resistance pattern } & MARS Index (a/b) \\
\hline $\mathbf{1}$ & Sm1 & 5 & AMP,TE,F,CFM,E & 0.46 \\
\hline $\mathbf{2}$ & Sb77 & 8 & C,AMP,AMC,TE,F,SXT,CFM,E & 0.73 \\
\hline $\mathbf{3}$ & Zc156 & 8 & CIP,AMP,K,AMC,TE,F,SXT,E & 0.73 \\
\hline $\mathbf{4}$ & Td5 & 8 & C,AMP,AMC,TE,F,SXT,CFM,E & 0.73 \\
\hline $\mathbf{5}$ & Tdn6 & 3 & AMP,AMC,CFM & 0.27 \\
\hline $\mathbf{6}$ & Tdn7 & 3 & AMP,AMC,CFM & 0.27 \\
\hline $\mathbf{7}$ & Tdn9 & 7 & CN,AMP,K,AMC,SXT,CFM,E & 0.64 \\
\hline $\mathbf{8}$ & Tdn40 & 4 & AMP,K,TE,CFM, & 0.36 \\
\hline
\end{tabular}

$a=$ Number of antibiotics each isolate was resistant to, $b=$ total number of antibiotics used $=11$, MAR $=$ Multiple Antibiotics Resistance (a/b).

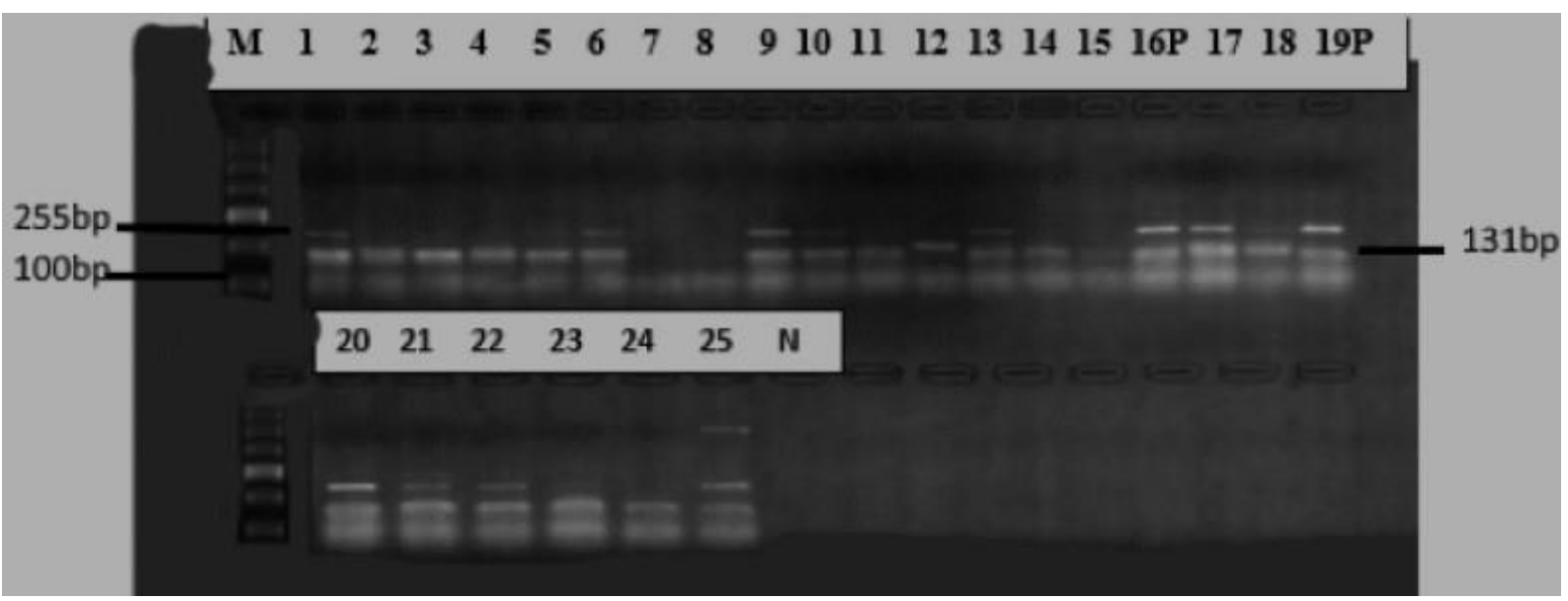

Figure 2: Agarose gel electrophoresis of Multiplex PCR amplification of the iap and inlA Virulence genes from meat samples DNA. Lane M 100bp molecular weight marker (Fermentas, USA); lanes1$15,17,18$, and 20-25 are samples positive for the target iap and inlA genes at $131 \mathrm{bp}$ and $255 \mathrm{bp}$, respectively, lane $\mathrm{N}$ is negative control (nuclease-free water), and lanes $16 \mathrm{P}$ and $19 \mathrm{P}$ are positive control specific for Listeria monocytogenes from ATCC.

\section{DISCUSSION}

The overall isolation rate of Listeria species in meat sampled in Zaria was $66(27.5 \%)$. This isolation rate is alarming because the Listeria species is regarded as one of the foodborne pathogens globally, especially in low-income countries like Nigeria. Moreover, the isolation of L. monocytogenes in this study may reflect the risk associated with consuming poorly cooked meat and the public health implication. The high isolation rate recorded in this study might be due to poor hygienic practices among the meat vendors, lack of application of hazard analysis of critical control point (HACCP) principles in the meat industries [25]. Secondly, the sources of Listeria species in this study may include faecal contamination during slaughter/processing by endogenous Listeria, cross-contamination from the environment, fomites (such as knives, head pans, meat-transport vehicles, and meat display tables), water used for washing carcasses and meat display tables, flies colonized with Listeria, and cloths/hands of butchers, meat-retailers, and buyers [18]. Listeria species can contaminate surfaces because of their ability to attach surfaces using peritrichous flagella and biofilm formation [26]. The level of Listeria monocygenes contamination found in this study is unsatisfactory and far away from the acceptable level $(<105)$ of microbial contamination set by the Codex Alimentarius Commission-CXG 77-2011 [27]. However, cross-contamination can also occur during further processing of carcasses at the processing plants, during distribution and storage of raw meat as described by [28]. 
In a previous study by [26] in Enugu State, Southeastern Nigeria, $45.8 \%$ of Listeria species was isolated from beef. This rate was higher than the isolation rate in the current study conducted in Zaria, North-western Nigeria. Another study also reported a higher isolation rate $(33.75 \%)$ in Port Harcourt, in the Niger-Delta region of Nigeria [29]. This might be as a result of differences in sampling technique, method of isolation and geographic location. The isolation rate recorded in this study was also lower than the previous study in Nigeria, in which Listeria species was isolated from chicken in Markudi, Benue State [30]. Similarly, in Ethiopia and Italy, [2] and [31] reported a lower isolation rate of $20.0 \%$ and $11.7 \%$ from beef, respectively. The disparities in the isolation rate might be due to differences in sampling technique, isolation and meat processing/hygienic practices.

The present study identified various Listeria species, including $L$. monocytogenes, $L$. grayi, $L$. innocua, and $L$. ivanovii, suggesting that diverse Listeria species contaminate fresh/raw meats in Zaria, Nigeria. The isolation of Listeria monocytogenes in this study is of significant public health importance because of its zoonotic implications in the food industry [32]. More importantly, in this study, L. monocytogenes isolation were higher in Tudun-Wada than in other locations. Meanwhile, the place has more anthropogenic (human) activities and poor hygienic practices than the other locations used in this study. Also, Tudun-Wada and Zaria city are further away from the abattoir than the other locations. Therefore, the meat samples were more exposed to the human factors that favour contamination with Listeria monocytogenes. Whereas, Listeria grayi, $L$. ivanovi and $L$. innocua were more frequently isolated from Dan-Magaji, Zaria city and Samaru, respectively, suggesting environmental contamination in these areas.

Furthermore, Listeria species were frequently isolated from the Reproductive tract and GIT than the other organs sampled in this study. This might be attributed to the practice of mixed livestock grazing and inter-herd movement, so the high isolation rate of Listeria species from the GIT and female reproductive tract could result from contamination of the grazing pasture and transmission via coitus, respectively. These findings are of significant public health importance because listeriosis is a meat-borne infection, and the offal is a special delicacy among the people in the study area. Hence, they are at risk of contracting the Listeria infection by consuming contaminated meat $[33,34]$. Moreso, water, soil and grasses are the significant sources of Listeria species infections in live animals; hence, the inter-herd transmission, cross-species transmission and consequently, the same trend could lead to the Animal-Human-Environmental interface.

Our study revealed a high resistance of $L$. monocytogenes $(\mathrm{n}=8)$ to Gentamycin $(87.5 \%)$, Kanamycin $(62.5 \%)$ and Ciprofloxacin $(62.5 \%)$. This finding might be due to the acquisition of resistance genes that code for resistance to the various antimicrobials from the environment and other enteric bacteria. Also, the indiscriminate use of antibiotics in Nigeria in Veterinary and human health could result in the "high selective pressure" observed in this study. The unregulated use of Gentamycin, Kanamycin and Ciprofloxacin in meat-producing animals coupled with poor environmental sanitation may also be responsible for the high resistance rate observed in this study. A similar finding has been reported in a study conducted on food animals in Nigeria by [35]. However, a contrary report was documented by [36] in a study conducted in Iran, in which there was high resistance of $L$. monocytogenes to $\beta$-lactams antibiotics. This finding suggested that the high percentage of multi-resistant isolates detected implies that new resistance genes may be acquired and transferred to other strains or other bacterial species or genera.

The high susceptibility of $L$. monocytogenes to Amoxycillin/Clavulanic acid (75.0\%), Cefixime $(87.5 \%)$ and Tetracycline $(87.5 \%)$, recorded in this study, is indicative of low usage of these antibiotics in meat-producing animals in the study areas. However, this may be due to laboratory limitations, since Gentamicin and Tetracycline derivatives are commonly used drugs in both Veterinary and human health in Nigeria.

Six of the isolates in this study were multidrugresistant (resistant to $\geq 3$ antibiotics of different classes), with the AMP-AMC-CHL-CFM-ERYF-SXT-TET multidrug resistance phenotypic expression being the most $(\mathrm{n}=2)$ occurring pattern. This may be due to the widespread abuse of these antibiotics in animal and human medicine across Nigeria. Multidrug resistance poses a severe threat to therapy in cases of 
listeriosis in both animals and humans. Various studies have proven that infections caused by multidrug-resistant Listeria monocytogenes strains are more dangerous than the infections caused by susceptible strains, because of the extensively delay in therapy and result in fatal outcomes $[37,38]$.

The phenotypic expression of resistance to antimicrobial agents observed in this study, was indicative of a wide diversity of resistance to many classes of antimicrobials used, such as aminoglycosides, and beta-lactams. But some of the isolates had shown a considerable number of susceptibilities to Cefixime and tetracyclines reflecting Cephalosporins and tetracycline derivatives, respectively. This clearly explains the possibility of conferring resistant and susceptibility genes among the food-borne pathogens over time, due to transformation and conjugation within the bacterial biofilms in food animals.

Previous studies had reported on the exchange of genetic materials, particularly the resistance and virulence gene under the concept of the animalhuman-environmental interface [39].

Furthermore, the study revealed that about eight (8) of the Listeria isolates in this study showed phenotypic multidrug-resistant expression with multiple patterns on antibiogram profile, suggesting the challenges in the emergence of MDR species with consequent complications in the clinical treatment of many foodborne diseases, in terms of multiple drug resistance and relapse. These findings are therefore, imperative to contribute to the development of effective policies and interventions for antibiotic stewardship in livestock production in Nigeria.

Similarly, [40] find out that there has been a low knowledge of antibiotic stewardship in countries such as Nigeria. In Nigeria, it was found that the majority of farmers were neither aware of nor comply with the mandatory withdrawal period after administering antibiotics [41], and that majority of farmers do not seek veterinary advice for disease diagnosis or an antibiotic prescription but, relied on personal experience, advice from other farmers or urban myths. Contrarily, in most high-income countries, national monitoring programs have been established to control the spread of antibiotic-resistance bacteria.

The virulence genes detected are similar to those observed in clinical isolates. The inlA encodes the surface protein inlA an essential element for the initial attachment and invasion of intestinal epithelial cells by Listeria [42]. Previous studies have reported that variability occurs in the carriage and detection of these genes among Listeria species related to the target fragments within the gene [43] and truncation in some genes such as internalin [44]. Listeriolysin $\mathrm{O}$ encoded by the hylA gene is a major virulence factor in Listeria and is considered essential for identifying $L$. monocytogenes. It was not detected among the L. monocytogenes isolates in the current study.

Similarly, a consistent observation has been made previously by [45], in which reported only the iap and inlA genes were reported, but no hylA detected. However, on the contrary, others detected the gene in only a few of the $L$. monocytogenes isolates in their study, as reported [13]. The unusual growth and survival properties of $L$. monocytogenes contribute to the complexity of producing Listeria free foods. The ability of the organism to survive and grow in refrigeration and freezing and re-contaminate other foods has important implications. A low initial inoculum in a portion of food at the time of manufacturing can translate into a substantial dose of Listeria for the consumer, depending on the shelf life and handling of a particular product as new food preparation methods are introduced to the public, the potential for transmission of Listeria spp. needs to be considered. The meat was chosen for this study because it provides an excellent medium for bacterial growth and multiplication. Meat is sold in various (local) forms and includes Balangu, Kilishi, and Suya of which have been shown to harbour (contain) the organism at even the point of sales [13]. Lastly, this may also be due to the principles of biofilm and gene transfer in the bacterial populations. In concordance with the above findings, [46] reported that effluents from processing facilities contributes to the spread of multidrug-resistant bacteria into the environment and finally to the human and animal health.

\section{CONCLUSIONS:}

In conclusion, the occurrence of clinically significant Listeria species and multidrugresistant Listeria monocytogenes harboring virulence markers, highlights the role that meat may play as a vehicle for the spread of this pathogen to susceptible humans. Also, the 
detection of multidrug-resistant $L$. monocytogenes raises the alarm for increased surveillance for this pathogen in food of animal origin. Attention also needs to be focused on the role meat and other foods of animal origin may play in the emergence of virulent and resistant $L$. monocytogenes. The study had established that $L$. monocytogenes and other species still occur in various degrees depending on the part of beef sampled, the processing method and the environment from which samples were obtained. These findings support other lines of evidence that food animals are emerging as essential reservoirs of multidrug-resistant Listeria species, which may cause severe diseases in humans and poses serious threats to public health. The Listeria isolates with multiple antimicrobial resistance genes may be transfered to humans through the food chain and thus, the need for further investigation and increased awareness among the livestock farmers in Zaria, on antibiotic usage and their withdrawal period. In the end, Standard Operating Procedures (SOP) and HACCP should be developed and implanted by all the stakeholders such as butchers association. Government should enforce periodic monitoring of all abattoirs in order to institute mitigation measures to check-mate the sanitary levels of the abattoirs and enforce strict adherence to hygienic standards. .

Funding sources: None.

Acknowledgement: The Authors appreciate the contributions of Dr. E. E. Francis and Dr. Sani Mohammed of the Faculty of Veterinary Medicine, University of Maiduguri. Also appreciate the Department of Veterinary Public Health and Preventive Medicine, Faculty of Veterinary Medicine, Ahmadu Bello University, Zaria for their support throughout the research work and the meat sellers involved in this study for their compliance during raw meat samples collection.

Conflicts of interest: None.

Consent for publication: Not applicable.

\section{HIGHLIGHTS:}

- Four different Listeria species were recovered from $27.5 \%$ of the 240 raw meat samples. The listeria species were L. grayi, $L$. innocua, $L$. monocytogenes and $L$. ivanovii 6 (9.1).
- High percentages of Ampicillin (100\%) and Tetracycline $(87.5 \%)$ susceptibility were found among the isolates. The $L$. monocytogenes displayed high rate of resistance to Ampicillin (100\%) and sensitivity to gentamicin (87.5\%). Isolates from Sabon-gari, Tudun Wada, and Zaria city had the highest Multiple AMR index (0.73).

- Two virulence genes were also identified: inlA 1 (12.5\%) and iap $5(62.5 \%)$. This revealed that Listeria monocytogenes are prevalent in meat samples in Zaria metropolis, have multiple AMR, and possess virulence genes.

- The Listeria isolates with multiple antimicrobial resistance genes may be transmitted to humans through the food chain and thus require further investigation and increased awareness, due to associated severe threats to public health.

- These findings support other lines of evidence that food animals are emerging as essential reservoirs of multidrug resistant Listeria species, which may cause diseases in humans.

\section{REFERENCES}

1. Indrawattana $\mathrm{N}$, Nibaddhasobon $\mathrm{T}$, Sookrung $\mathrm{N}$, Chonga-nguan M, Tungtrongchitr A, Makino, S, et al. Prevalence of Listeria monocytogenes in raw meats marketed in Bangkok and characterisation of the isolates by phenotypic and molecular. $J$ Health Popul Nutr. 2011; 29:26 - 38.

2. Garedew L, Taddese A, Biru T, Nigatu S, Kebede E, Ejo M, et al. Prevalence and antimicrobial susceptibility profile of Listeria species from ready-to-eat foods of animal origin in Gondar Town, Ethiopia. BMC Microbiol. 2015; 15:100.

3. Wu S, Wu Q, Zhang J, Chen M, Yan Z, Hu H. Listeria monocytogenes prevalence and characteristics in retail raw foods in China. PLoS ONE 2015; 10(8): e0136682.

4. WHO. Joint FAO/WHO Microbial Risk Assessment Series: Risk assessment of Listeria monocytogenes in ready-to-eat foods: Technical report. (Microbiological risk assessment series; no. 5). 2018; Listeriosis (who.int). (Accessed October, 20th, 2021).

5. Zhu Q, Gooneratne R, Hussain MA. Listeria monocytogenes in Fresh Produce: Outbreaks, Prevalence and Contamination Levels. Foods. 2017; 6: 21. doi:10.3390/foods6030021. 
6. Dorcheh MP, Sohrabi R, Salajegheh M. Prevalence of Listeria species in retail quail products from Isfahan, Iran. J. Vet. Med. 2013; $5: 16-19$.

7. Haase JK, Didelot X, Lecuit M, Korkeala H, Achtman M. The ubiquitous nature of Listeria monocytogenes clones: a large-scale multilocus sequence typing study. Env Microbiol. 2014; 16:405-416. 10.1111/1462-2920.12342.

8. Aras Z, Ardıç M. Occurrence and Antibiotic Susceptibility of Listeria Species in Turkey Meats. Korean J Food Sci Anim Res. 2015; 35(5): 669673. http://doi.org/10.5851/kosfa.2015.35.5.669.

9. Ishola OO, Mosugu JI, Adesokan HK. Prevalence and antibiotic susceptibility profiles of Listeria monocytogenes contamination of chicken flocks and meat in Oyo State, south-western Nigeria: Public health implications. J Prev Med \& Hyg. 2016; 57(3): E157-E163.

10. Rocourt J, Cossart P. Listeria monocytogenes. In: Doyle, M.P., Buechat, L.R., Montville, T.J. (Eds.), Food Microbiology - Fundamentals and Frontiers. Amer Soc Microbiol. (ASM) press, Washington DC 1997; 337-352.

11. Nwaiwu O. A case for increased surveillance of Listeriosis by using clinical samples in Nigeria. Sci African. 2020; 7. e00320. 10.1016/j.sciaf.2020.e00320.

12. Nwaiwu O. (2015). Overview of Listeria species in Nigeria. Int Food Res J. 2015; 22:455-464.

13. Ndahi MD, Kwaga JKP, Bello M, Kabir J, Umoh VJ, Yakubu SE. prevalence of antimicrobial susceptibility of Listeria monocytogenes and methicillin-resistant Staphylococcus aureus strains from raw meat and meat products in Zaria, Nigeria. Applied Microbiol. 2014; 58: 262-269.

14. Dhand, N.K. and Khalkar, M.S., 2014. Stiatulator St1atistical Program.

15. Thrusfield M, Christley R, Brown H, Diggle PJ, French N, Howe K. First published: 23 February 2018. https://doi.org/10.1002/9781118280249.

16. Vanderzant C, Splittstoesser D. Compendium of Methods for the Microbiological Examination of Foods. 3rd Edition: 1992, Amer Publ Health Assoc. Washington DC.

17. Hitchins AD, Whiting RC. Food-borne Listeria monocytogenes risk assessment (2001). Food Addit Contam. 2001; 18(12):1108-17. doi:10.1080/02652030110050104. PMID: 11761122.

18. Silva AS, Elizabeth AA Duarte, Thiago AS De Olivera, Norma S Evangelista-Barreto. Identification of Listeria monocytogenes in cattle meat using biochemical methods and amplification of the hemolysin gene. Anais $d a$ Academia Brasileira de Ciencias, 2020;, 92(1): 1678-2690. Doi.org/101590/00013765202020180557.

19. Mira-Gutierrez, J., Perz De Lara C. and Rodriguez-Igesias, M. A. (1990). Identification of species of the genus Listeria by fermentation of carbohydrates and enzymatic patterns. Acta Microbiol. Hungarica.1990; 37:123-129.

20. CLSI Catalogue. The Clinical and Laboratory Standards Institute Catalog 2019. https://clsi.org/media/3062/clsi-update2019_21819_final_fullsizedhandouts.pdf

21. Mandrekar, P. Introduction to Nucleic Acid Purification: Purification Basics and Their Application to Different Sample Types. 2016; https://www.promega.com. (Accessed, Oct., 21st 2021).

22. Wang, Z. and Rossman, T.G. Isolation of DNA fragments from agarose gel by centrifugation. Nucl. Acids Res. 1994; 22:2862-3.

23. Furrer B, Candrian V, Hofelein C, Luthy J. Detection and identification of Listeria monocytogenes in cooked sausage products and in milk by in vitro amplification of haemolysin gene fragments. J Appl Bacteriol. 1991; 70:372-379.

24. Usman UB, Kwaga JKP, Kabir J, Olonitola OS, Radu S, Bande F. Molecular characterization and phylogenetic analysis of Listeria monocytogenes isolated from milk and milk products in Kaduna, Nigeria. Can J Infect Dis Med Microbiol. 2016; 17.

25. Henry CJ, Xin JL. Application of Hazard Analysis Critical Control Point in the local manufacture of ready-to-use therapeutic foods (RUTFs). Food Nutr Bull.2014; 35(2 Suppl):S57-63. doi: 10.1177/15648265140352S109. PMID: 25069295.

26. Okorie-Kanu, OJ, Anyanwu MU, Ezenduka EV, Mgbeahuruike AC, Okorie-Kanu CO, Ugwuijem EE, et al. Occurrence and antibiogram of Listeria species in raw pork, beef, and chicken meats marketed in Enugu State, Southeast Nigeria. Vet. World. 2020;13(2):317-325.

doi: 10.14202/vetworld.2020.317-325.

27. Codex Alimentarius Commissoion, FAO/WHO (2011). Joint FAO/WHO Food Standards Programme Codex Committee on Contaminants in Foods. Fifth Session, 21-25 March 2011.

28. Abdissa, R., Haile, W., Fite, T. A, Beyi AF, Agga GE, Edao BM et al. (2017). Prevalence of Escherichia coli O157: $\mathrm{H} 7$ in beef cattle at slaughter and beef carcasses at retail shops in Ethiopia. BMC Infect Dis. 2017; 17(1):1-6.

29. Eruteya, Onoriode. (2014). Listeria species in Raw Coe Goat Meat in Port Harcourt, Nigeria. 
British Biotechnol J. 2014; 4: 204-214. Doi/10.9734/BBJ/2014/6750.

30. Daniel ST, Umeh EU, Iheukwumere CC. Contamination and Antibiotic Susceptibility Profile of Listeria Species in Frozen and Fresh Chicken Sold in Makurdi, Nigeria. Intl J Curr Microbiol App Sci. 2015; 4(7):617-623.

31. Pesavento G, Ducci B, Nieri D, Comodo N, Lo Nostro A. Prevalence and antibiotic susceptibility of Listeria spp. isolated from raw meat and retail foods. Food Control. 2010;21(5):708-713. doi:10.1016/j.foodcont.2009.10.01

32. Shamloo E, Hosseini H, Abdi Moghadam Z, Halberg Larsen M, Haslberger A, Alebouyeh M. Importance of Listeria monocytogenes in food safety: a review of its prevalence, detection, and antibiotic resistance. Iranian J Vet Res. 2019; 20(4):241-254.

33. Buchanan Robert L, Leon GM, Gorris Melinda M, Hayman Timothy C, Jackson Richard CW. A review of Listeria monocytogenes: An update on outbreaks, virulence, dose-response, ecology, and risk assessments. Food Control. 2017; 75(17): Pp1-

13.https://doi.org/10.1016/j.foodcont.2016.12.016.

34. EFSA BIOHAZ Panel (EFSA Panel on Biological Hazards), Ricci A, Allende A, Bolton D, Chemaly M, Davies R, Fernandez ESC et al. Scientific Opinion on the Listeria monocytogenes contamination of ready-to-eat foods and the risk for human health in the EU. EFSA J. 2018;16(1):5134, 173 pp. https://doi.org/ $10.2903 /$ j.efsa. 2018.5134

35. Oloso NO, Fagbo S, Garbati M, Olonitola SO, Awosanya EJ, Aworh MK, et al. Antimicrobial resistance in food animals and the environment in Nigeria: a review. Intl J Env Res Publ Health. 2018; 15(2018):1284.

36. Fallah Aziz AS, Saei-Dehkordi S, Rahnama M, Tahmasby H, Mahzounieh M. Prevalence and antimicrobial resistance patterns of Listeria species isolated from poultry products marketed in Iran. Food Control 2012; 28(2):327-332, https://doi.org/10.1016/j.foodcont.2012.05.014.

37. Krupp K, Madhavaram P. Antibiotic resistance in prevalent bacterial and protozoan sexually transmitted infections. Indian J Sex Transm. Dis. 2015; 36(1):3-8. http://doi.org/10.4103/02537184.156680 .
38. Llor C, Bjerrum L. Antimicrobial resistance: risk associated with antibiotic overuse and initiatives to reduce the problem. Therapeutic Advances in Drug Safety. 2014; 5(6):229-241. http://doi.org/10.1177/2042098614554919.

39. Iramiot, J., Kajumbula, H., Bazira, J, Kansiime C, Asiimwe BB. (2020). Antimicrobial resistance at the human-animal interface in the communities of Kasese District, South Western Uganda. Sci Rep. 2020; 10:147-37.

40. Katakwebe, A. A. S., Mtambo, M. M. A.,Olsen, J. E., Muharwa, A. P. Awearness of human health risks among livestock keepers and factors that contribute to selection of antibiotic resistance bacteria within livestock in Tanzania. Livestock Res Rural Dev. 2012; 24(10):Article170 ref.10.

41. Nsofor, C.A,. Iroegbu, C. U. (2013). Antibiotic resistance profile of Eschertichia coli isolated from five major geopolitical zones of Nigeria. $J$ Bacteriol Res. 2013; 5(3):29-34.

42. 42. Ferreira de Silva M, Ferreira V, Magalhaes R, Almeida G, Alves A, Teixeira P. Detection of premature stop codons leading to truncated internalin A among food and clinical strains of Listeria monocytogenes. Food Microbiol. 2017; 63:6-11.

43. Jacquet C, Doumith M, Gordon JI, Martin PM, Cossart P, Lecuit M. A molecular marker for evaluating the pathogenic potential of foodborne Listeria monocytogenes. J. Infect. Dis. 2004; 189:2094-2100.

44. Du XJ, Zhang X, Wang XY, Su YL, Li P, Wang S. Isolation and characterisation of Listeria monocytogenes in Chinese food obtained from the central area of China. Food Control 2017; 74:916.

45. Al-Nabulsi AA, Osaili TM, Awad AA, Olaimat AN, Shaker RR, Holley RR. Occurrence and antibiotic susceptibility of Listeria monocytogenes isolated from raw and processed meat products in Amman, Jordan. CyTA J Food. $2015 ; 13: 346-352$.

46. Projan, S. Antibodies for the Prevention Treatment, and Preemption of Infectious Diseases. In book: Protein Therapeutics. 2017; http://doi.org/10.1002/9783527699124.ch18 